American J. of Engineering and Applied Sciences 2 (1): 25-30, 2009

ISSN 1941-7020

(C) 2009 Science Publications

\title{
Effect of Joint Flexibility on Overall Behavior of Jacket Type Offshore Platforms
}

\author{
Masoud Mirtaheri, Hossein Ali Zakeri, Pejman Alanjari and Mohammad Amin Assareh \\ Khajeh Nassir Toosi University of Technology, Civil Faculty, P.O. Box 15875-4416, Tehran, Iran
}

\begin{abstract}
Problem Statement: Nonlinear behavior of offshore structure is attracting tremendous amount of attention in recent years. Response of these structures is strictly dependent upon behavior of their joints. Because of the lack of information about this part of a structure, most of the recent analysis and designs do not contain appropriate material in the case of joints. In most cases, joints are assumed to be fully clamped and their deformability is not accounted for in assessment of Jacket Type Offshore Platforms (JTOP) whereas, in reality there is always deformation in joints particularly when members undergo beyond elastic region. Approach: In this study, finite element modeling of tubular connections is carried out in order to assess their nonlinear behavior. As a result in a separate study, two FE models of a platform are made and effect of joint flexibility on these models is investigated analytically. Nonlinear static and dynamic analyses are performed considering joint deformation and compared to platform with clamped connections. Furthermore, some important parametric studies are carried out such as effect of joint flexibility on natural frequency of vibration of the structure and the process of plastic hinge formation in platform. Results: Results prove considerable effect of local joint deformation on nonlinear static and dynamic behavior of offshore structures. Conclusions/Recommendations: Taking into account the calculated results in this paper, it is highly recommended to consider the effect of joints in the design and analysis of offshore structures based on the importance of the project.
\end{abstract}

Key words: Natural frequency, nonlinear dynamic analyses, jacket type offshore platform, joint flexibility

\section{INTRODUCTION}

Almost $30 \%$ of total energy devoted in man's life is extracted from offshore oil and gas resources. Interaction between human's need for energy and financially-driven problems involving projects to be cost-effective, have always been widespread debate among engineers. Because of the huge up-front investment in production platforms, modestly-sized hydrocarbon discoveries in deep water are not economic. But in shallow or moderately-deep water, fixed offshore platforms are utilized to produce oil and gas from marginal fields. Design of JTOPs depends upon service and instrumental loads as well as environmental loads including wave, current, wind and earthquake.

Tubular members are mainly used to withstand these abovementioned loads since they are hollow and can effectively produce buoyancy upon installation. These members are applicable not only in offshore industry but also in manufacturing of space truss structures, telecommunication towers, crane structures and so on. Moreover, they are superior in comparison with other cross sections in several aspects such as high torsional strength, symmetry in cross section, almost perfect feasibility in welding of connections and being economical when used in design. Considering these parameters, the study of tubular connections are becoming of great importance in recent years.

There are basically two major methods for studying the behavior of connections namely (1) empirical relations resulted from experimental tests on individual connections and (2) analytical finite element models simulating the behavior of full-scaled connections. The latter is divided into two groups. Uniaxial elements are used in place of connection with governing loaddeformation relationships in first group whereas in second group, multi-axial analytical FE models form connections and load-deformation and/or momentrotation relations are obtained explicitly.

Several researchers have investigated the behavior and assessment of tubular connections. Ueda et al., ${ }^{[1]}$

Corresponding Author: Mohammad Amin Assareh, K.N. Toosi University of Technology, P.O. Box 15875-4416, Vali Asr St., Mirdamad Blvd., Tehran, Iran Tel: +98-912-1944337 Fax: +98-261-4314773 
studied the response of joints based on uniaxial elements and bilinear elastic-plastic behavior. Chen et al., ${ }^{[2]}$ used a semi-analytical method to extract general flexibility relationships. Honarvar et al., ${ }^{[3]}$ studied the effect of joint-cans on overall behavior of JTOPs with different pile-leg interactions based on experimental and analytical methods. Boukamp et al., ${ }^{[4]}$ utilized FE shell elements to simulate individual joints and studied their effect on structural response of offshore platforms.

In this study, in analogous way to Boukamp ${ }^{[4]}$, individual full scale tubular connections are modeled with the aid of multi-axial shell elements and loaded to reach moment-rotation relations. The effect of axial force in braces on moment-rotation relations is studied subsequently. Two types of connections which are frequently used in offshore platforms are examined namely $\mathrm{T}$ and $\mathrm{Y}$ connections and loaded to test their rotations in comparison with fully rigid assumption. Moreover, in a separate study, two FE model of an offshore platform (platform with rigid and flexible connections) are built and analyzed to investigate the effect of joint flexibility on overall behavior of offshore installations.

\section{MATERIALS AND METHODS}

In order to obtain load deformation relationships in a tubular joint, one should study the membrane-bending theory as well as large deformation effects. When the applied forces on the joints are increased progressively, large local deformations may cause highly nonlinear responses which should be taken care of using suitable analytical method. Recent experiments show that tubular connections are capable of carrying loads beyond elastic region and the amount of force required for total failure of connections are significantly greater than those loads which cause initial yielding ${ }^{[4]}$. When a certain point yields, it loses its load carrying capacity and transfers induced stress to neighboring regions so that the connection will be able to carry input forces. One can exert external force and/or moments to connections beyond their elastic limits to obtain loaddeflection behavior prior to total failure.

Two types of tubular connections are studied individually. The first case is T-type connection for which strut is perpendicular to the leg and the second case is Y-type connection for which strut approaches the leg obliquely. Figure 1 shows a typical Y-type connection and the selected length of leg and strut which is to be modeled. It should be noted that $\mathrm{T}$ type connection is a special case of Y-type connection in which intersection angle $\phi$ is $90^{\circ}$. FE program Ansys is used throughout this study for modeling and analyses as it has an extensive range of sophisticated elements suitable for modeling highly nonlinear shells having large deformation capability.

Bilinear kinematic hardening material is used to represent steel material with 0.003 strain hardening ratio. Table 1 shows material and geometrical properties used for modeling the connections.

Static progressively-increasing loading is applied on the strut, $2500 \mathrm{~mm}$ away from intersection point and continued beyond elastic region to cover a wide range of response including elastic and plastic rotations.

Figure 2 illustrates $\mathrm{FE}$ model of typical connections generated through the use of shell elements and dense mesh discretization in intersection region to capture nonlinear strains as accurately as possible.

After performing nonlinear push-over static analyses, one can obtain moment-rotation relationships of several connections with different intersection angles. Figure 3 shows stress distribution of von-misses type resulted from

static analysis for aforementioned connections. As can be observed, maximum combined stress is induced in intersection of outer wall of struts with legs where welding is normally carried out in practice.

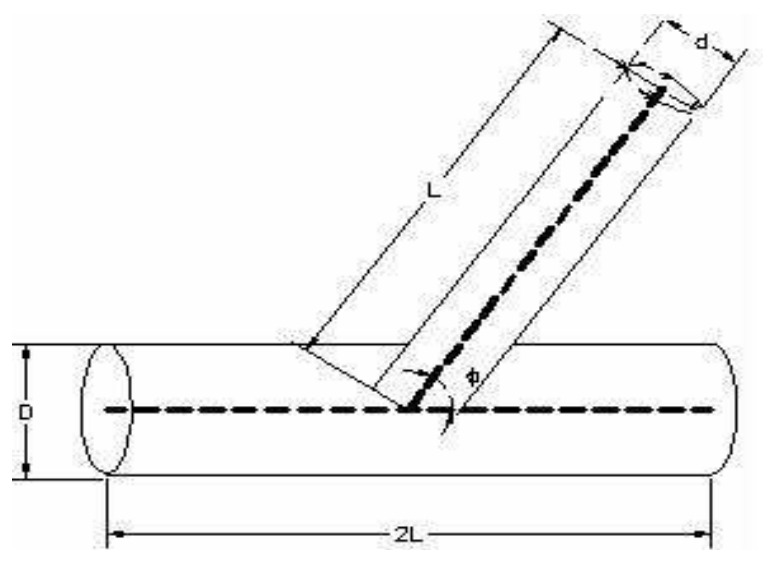

Fig. 1: Y-type tubular connections 
Am. J. Engg. \& Applied Sci., 2 (1): 25-30, 2009

Table 1: Material and geometrical properties used for modeling the connections

\begin{tabular}{lllll}
\hline Geometrical properties & & Material properties & \\
\hdashline & & & \\
Member type & Tube Diameter (mm) & Wall Thickness $(\mathrm{mm})$ & Yield stress $\left(\mathrm{kg} \mathrm{mm}^{-2}\right)$ & 36 \\
\hline Main member (leg) & 1727 & 32 & E $\left(\mathrm{kg} \mathrm{mm}^{-2}\right)$ & 20000 \\
Secondary member (strut) & 610 & 19 & Poisson ratio & 0.3 \\
\hline
\end{tabular}
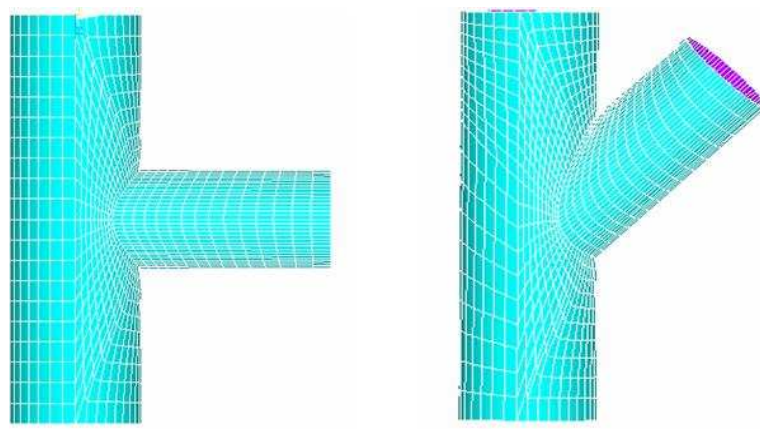

Fig. 2: FE model and mesh discretization for $\mathrm{Y}$ and $\mathrm{T}$ type connections
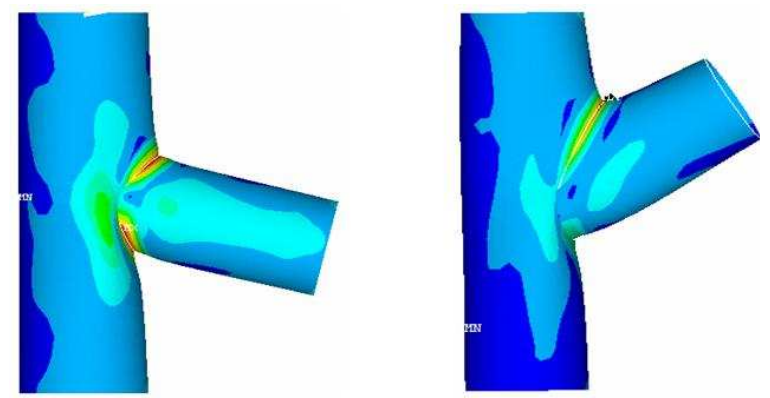

Fig. 3: Von-misses stress induced in connections

Table 2: 5 models, each having 5 initial axial loads

\begin{tabular}{lllll}
\hline Intersection & \multicolumn{2}{c}{ Model no. } & \multicolumn{2}{c}{ Initial axial } \\
& angle $\left(\Pi^{\circ}\right)$ & & & loads $\left(\mathrm{Kg} \mathrm{cm}^{-2}\right)$ \\
\hline Models with & 30 & Individual & 1 & -1200 \\
Different & 45 & model & 2 & 600 \\
intersection & 60 & & 3 & 0 \\
angles & 75 & & 4 & 600 \\
& 90 & & 5 & 1200 \\
\hline
\end{tabular}

It should be noted that loading procedure consists of 5 different scenarios for 5 different intersection angles. Initially, axial internal loads are induced in the struts to represent axial loads which normally exist in an offshore structure having braces. Afterwards, lateral progressively-increasing rotation (displacement control approach) is applied to represent external rotations and obtain corresponding moments. Therefore, 25 models are created and analyzed in this way Table 2 . Furthermore, ultimate rotation is defined as 0.03rad to control the amount of rotation.
Figure 4 shows obtained moment-rotation relationships for 4 models namely 30, 45, 60 and $90^{\circ}$. Closer investigation on above graphs shows the considerable effect of initial axial loads in struts on flexural capacity of the connections. As the initial load moves from compression towards tension, the capacity of the connection is increased and vice versa. This proves the effect of stress-stiffening in struts on the behavior and capacity of joints which basically states that tensile axial load strengthens the strut as well as its joint.

This is directly relevant to local buckling reduction due to tensile forces whereas, compressive stress causes local buckling of plates to be encountered more quickly. Moreover, it can be clearly seen that joints are not perfectly rigid and they show flexibility when loaded laterally. This flexibility assists the energy dissipation of the structure and should be accounted for when precise deformability of the platform is to be obtained.

Modeling the platform: Previously defined that connections are not perfectly rigid and their flexibilities should be considered when precise strength and stiffness of the platform are to be obtained. Two FE model of a 2D frame of an offshore platform are designed $^{[5]}$ and generated analytically and studied comparatively to gain insights about performance of platforms with rigid and flexible connections. The first model is made by means of uniaxial beam-column elements in which connections are assumed to be fully rigid whereas, the second model is generated through the use of 3D shell elements in which case, flexibilities of the joints are accounted for automatically. Figure 5 shows general configuration of

\begin{tabular}{llll}
\multicolumn{2}{l}{ Table 3: Natural periods of vibration of two platforms } \\
\hline & $\begin{array}{l}\text { Model with } \\
\text { flexible } \\
\text { connections }\end{array}$ & $\begin{array}{l}\text { Model with } \\
\text { rigid } \\
\text { connections }\end{array}$ & $\begin{array}{l}\text { Percentage } \\
\text { of } \\
\text { discrepancy }\end{array}$ \\
\hline 1 & 2.313 & 2.026 & 12.4 \\
2 & 2.065 & 1.916 & 7.215 \\
3 & 1.943 & 1.818 & 6.427 \\
4 & 0.635 & 0.608 & 4.318 \\
5 & 0.435 & 0.424 & 2.521 \\
6 & 0.371 & 0.368 & 0.761 \\
7 & 0.672 & 0.663 & 1.378 \\
8 & 0.341 & 0.333 & 2.214 \\
9 & 0.379 & 0.375 & 1.037 \\
10 & 0.317 & 0.310 & 2.115 \\
\hline
\end{tabular}




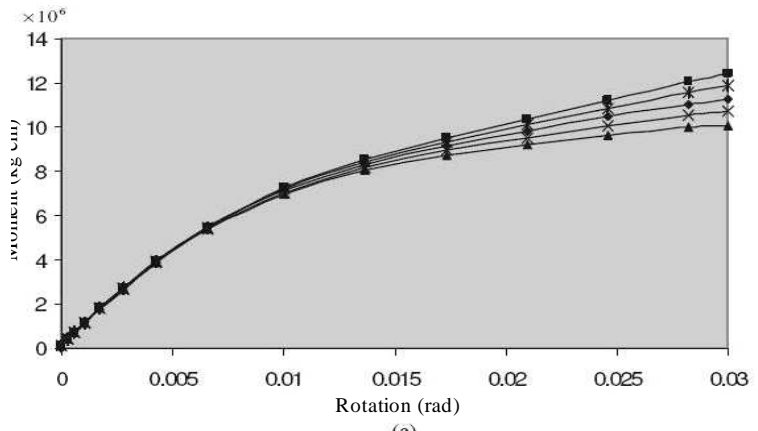

(a)

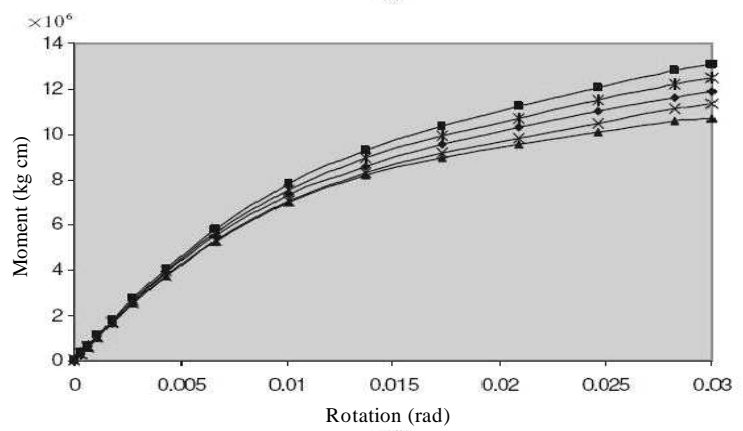

(b)

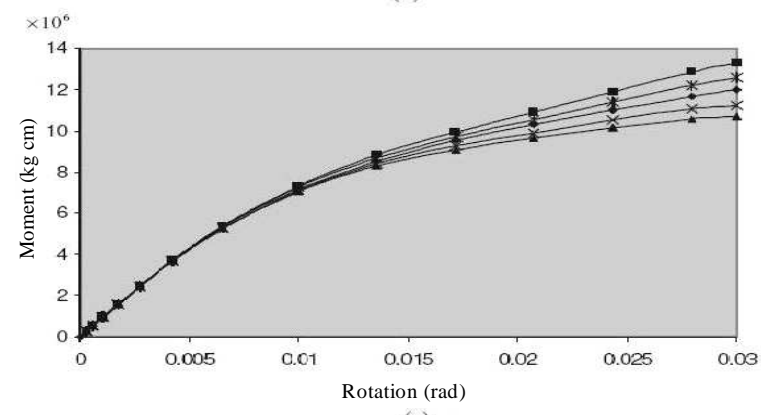

(c)

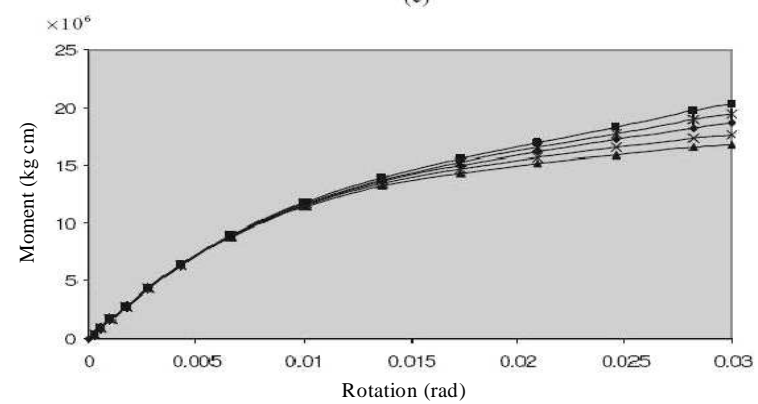

(d)

$\rightarrow$ MODEL1 $\rightarrow$ MODEl2 $\rightarrow$ MODEL3 $\rightarrow$ MODEL5 $\rightarrow$ MODEL5

Fig. 4: Moment-rotation relationships of $\mathrm{Y}$ and $\mathrm{T}$ type tubular connections

the 2D model frame and member sizes used in the modeling. It should be noted that overall behavior of jacket structure is focused on and consequently piles have not been modeled and legs are restrained in mudline elevation.

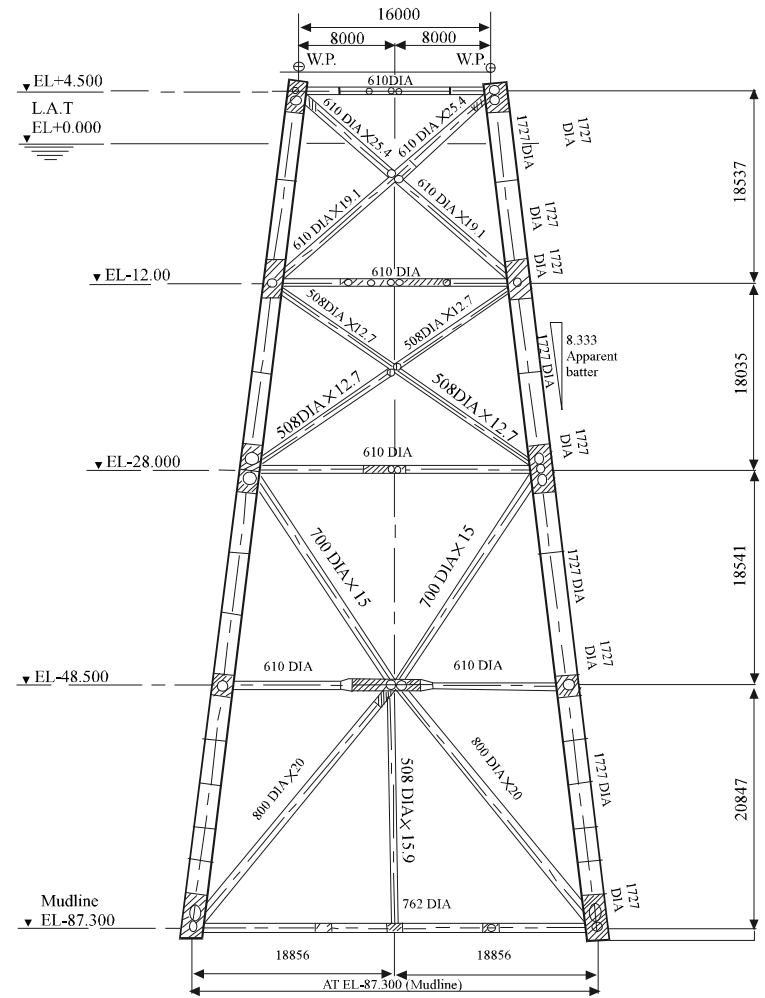

Fig. 5: General configuration and member sizes for 2D frame

\section{RESULTS}

Modal analysis: Modal analysis was performed on both structures and results are presented herein. As can be observed in Table 3, modal responses of the platforms are different.

These differences stem from rigidities considered in model with uniaxial elements. Obviously, platform with flexible connections show higher periods due to deformability considered in the model.

Nonlinear static and dynamic analyses: Nonlinear push-over analysis was performed in such a way that first mode shape of vibration was selected as load pattern. Loading was incremented beyond elastic strength to compare strength and stiffness of two structures not only in elastic region but also in inelastic responses. Figure 6 shows base shear-deck displacement graphs of two platforms. As it is seen, platform with rigid connection is considerably stiffer. Over-strength and stiffness become more significant when inelastic responses are encountered. One can conclude that disregarding joint flexibilities may yield relatively overestimation of lateral capacity of the structure and may result in non-conservative design. 


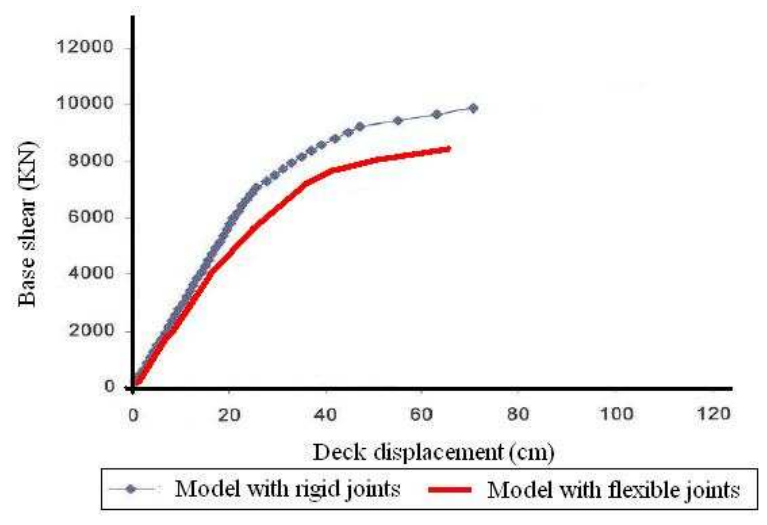

Fig. 6: Results of push-over analysis

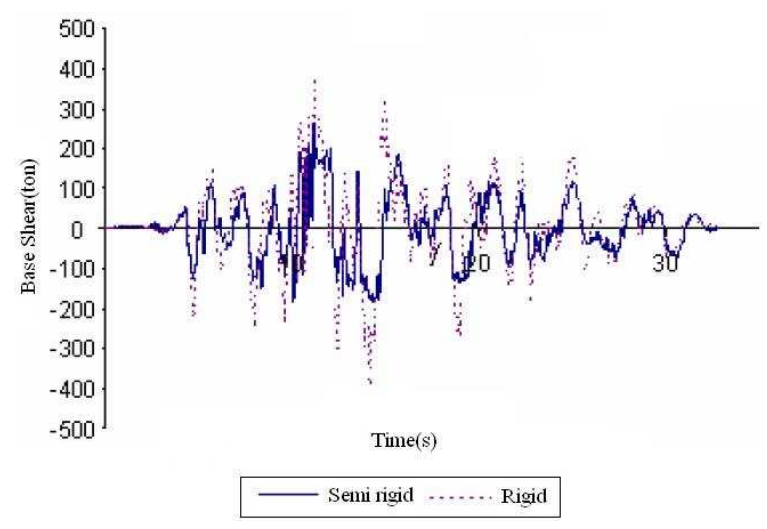

Fig. 7: Results of nonlinear dynamic analysis on both models (Tabas record)

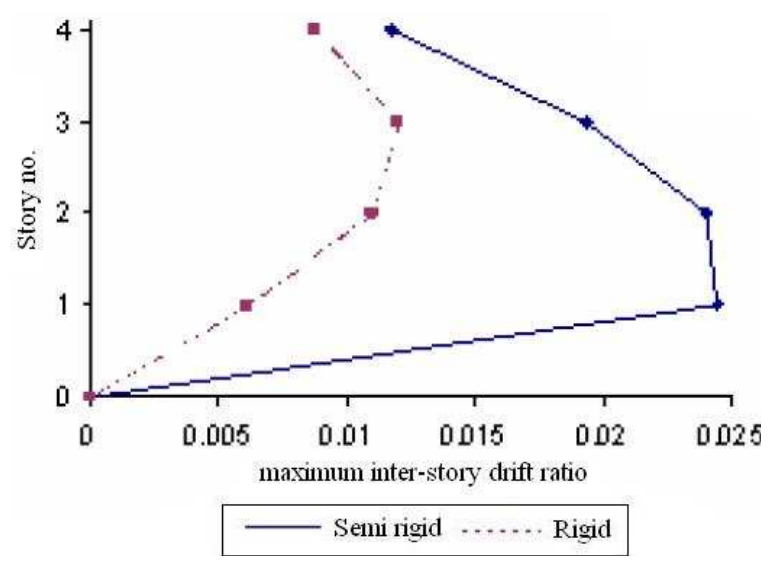

Fig. 8: Maximum inter-story drift ratio of two models subjected to Tabas EQ record

Moreover, nonlinear time-history analysis was performed on both structures using Tabas earthquake record and base shear of the platforms were monitored accordingly and comparative results are presented in Fig. 7. Higher base shears induced in model with rigid connections are quite apparent as the structure is stiffer and as a consequence internal forces tend to be greater.

\section{DISCUSSION}

A good representation of structural response to strong earthquake motions is inter-story drift ratio through the height of the structure. Figure 8 shows maximum inter-story drift ratio for two models when subjected to Tabas earthquake. As it is seen in this figure, first story shows highest drift among other stories. Additionally, more flexibility of the shell element-made model is emphasized in this Figure.

\section{CONCLUSION}

Joint flexibility and its effect on local and global behavior of the jacket type offshore platforms were studied in this research and following conclusions can be reached:

- Tubular connections used in offshore industry are intrinsically flexible. This is in contrast with usual practice in which joints are assumed to be fully rigid. Knowing the fact joints are flexible and are able to dissipate energy when subjected to cyclic forces, one can conclude that disregarding the joint flexibility in estimation of overall energy dissipation, presents inaccurate results

- Compressive axial forces in struts reduces the strength of the end connections as they increase the susceptibility of local buckling in joints unlike the tensile forces which assist the strength of the connections and prevent local buckling occurrence

- Results of pushover analysis indicate that the effect of joint flexibilities become more apparent when a structure undergoes beyond elastic region and shows nonlinear behavior

- Modal characteristics of two frames show that considering joint flexibility in the model results in 12.4 percent increase in primary period of vibration which is quite appreciable

- Nonlinear dynamic analysis is performed on both structures and results indicate the fact that platform with flexible connections shows higher displacements and inter-story drifts and lower base shear due to less stiffness and strength of the jacket structure 


\section{REFERENCES}

1. Ueda, Y., S. Rashed and K. Nakacho 1990. An improved joint model and equations for flexibility of tubular joints. J. Offshore Mech. Arctic Eng., 112: $157-168$.

DOI: $10.1115 / 1.2919850$

2. Chen, T. and Zhang H., 1996. Stress analysis of spatial frames with consideration of local flexibility of multiplanar tubular joint. Engineering Structures, Volume 18, Issue 6, Pages 465-471 Doi: 10.1016/0141-0296(95)00109-3

3. Honarvar, M.R., M.R. Bahaari, B. Asgarian and P. Alanjari, 2007. Cyclic inelastic behavior and analytical modeling of pile-leg interaction in jacket type offshore platforms. J. Applied Ocean Res., 29: $167-179$.

DOI: 10.1016/j.apor.2008.02.001.
4. Bouwkamp, J.G. et al., 1980. Effects of joint flexibility on the response of offshore towers. In Proceedings of Offshore Technology Conference, May 5-8, 4: 455-464.

url:http://www.onepetro.org/mslib/servlet/onepetro preview?id=OTC-3901MS\&soc $=$ OTC\&spe AppNameCookie $=$ ONEPETRO

5. API. Recommended Practice for Planning, Designing and constructing Fixed Offshore Platforms - Working Stress Design. API-1993 (RP2A-WSD).

url:http://global.ihs.com/search_res.cfm?currency_ code $=$ USD\&customer_id=2125472B2B0A\&shopp ing_cart_id=282458232F49502C4D5A4D30260A $\&$ rid=API1\&country_code $=$ US\&lang_code $=$ ENG $\mathrm{L}$ 